\title{
Randomized Controlled Pilot Trial of Truncal Exercises after Stroke to Improve Gait and Muscle Activity
}

\author{
Byoung-Sun Park ${ }^{1 *}$, Ji-Woong Noh ${ }^{*}$, Mee-Young Kim¹, Lim-Kyu Lee1, Seung-Min Yang1, \\ Won-Deok Lee', Yong-Sub Shin1, Ju-Hyun Kim² ${ }^{2}$, Jeong-Uk Lee ${ }^{3}$, Byong-Yong Hwang 4 , Junghwan Kim ${ }^{4 \#}$ \\ ${ }^{1}$ Laboratory of Health Science \& Nanophysiotherapy, Department of Physical Therapy, Graduate School, Yongin University, Yongin, Korea \\ ${ }^{2}$ Department of Physical Therapy, College of Health Welfare, Wonkwang Health Science University, Iksan-Si, Korea \\ ${ }^{3}$ Department of Physical Therapy, College of Health Science, Honam University, Eodeung-Daero, Korea \\ ${ }^{4}$ Department of Physical Therapy, College of Public Health \& Welfare, Yongin University, Yongin, Korea \\ Email: "junghwankim3@yongin.ac.kr
}

How to cite this paper: Park, B.-S., Noh, J.-W., Kim, M.-Y., Lee, L.-K., Yang, S.-M., Lee, W.-D., Shin, Y.-S., Kim, J.-H., Lee, J.-U., Hwang, B.-Y. and Kim, J. (2016) Randomized Controlled Pilot Trial of Truncal Exercises after Stroke to Improve Gait and Muscle Activity. Neuroscience \& Medicine, 7, 149-156.

http://dx.doi.org/10.4236/nm.2016.74015

Received: September 8, 2016

Accepted: November 20, 2016

Published: November 23, 2016

Copyright $\odot 2016$ by authors and Scientific Research Publishing Inc. This work is licensed under the Creative Commons Attribution International License (CC BY 4.0).

http://creativecommons.org/licenses/by/4.0/

\begin{abstract}
The purpose of the present study was to evaluate the effects of a trunk exercise program on the gait and muscle activity in stroke patients. The participants of this pilot study included six hemiplegic stroke patients. The outcomes were surface electromyography (sEMG) and spatiotemporal gait parameters. In analysis of sEMG, no statistically difference was found between pre- and post-training of Maximal Voluntary Isometric Contraction (MVIC) in rectus abdominis and external abdominal oblique muscle, but it tended to increase. However, the gait parameter significantly increased in walking speed, walking cycle, and affected stride length in stroke patients. These results suggest that the trunk exercise program may in part improve the gait of chronic stroke patients.
\end{abstract}

\section{Keywords}

Trunk Exercise Program, Surface Electromyography, Chronic Stroke Patients

\section{Introduction}

Recently, many results from research on the relationship between trunk muscle activity and the gait function of hemiparesis patients have been reported [1] [2] [3] [4]. Trunk muscles have broad anatomical origins and insertions that are linked to several structures, such as spine, pelvis, rib cage and shoulder girdle. The trunk muscle affects post-

\footnotetext{
${ }^{\star}$ The first 2 authors (Park BS and Noh JW) contributed equally to this work.
} 
ure and movement of limbs, and thus it is related to walking ability [5]. A stroke patient shows muscle weakness, abnormal muscle tone, and a disorder in balance and posture control, which results in difficulty in locomotion [6]. Hemiparesis caused by upper motor lesions is known to be more detrimental to the distal than to the proximal body musculature [7] [8]. According to Davies, the "loss of selective trunk control" is the major functional deficit of post-stroke patients [9] [10]. The loss of selective trunk muscle control leads to abnormal gait parameters. Trunk exercises have a beneficial effect on trunk function, standing balance, and mobility in people after a stroke, and it is especially effective in improving balance, gait and functional ability [3]. Many studies have been conducted on the effect of trunk exercise on gait ability in stroke patients. However, studies on the effect of trunk exercise on trunk muscle activity and spatiotemporal gait parameter after trunk exercise for stroke patients are rare. Therefore, this study aimed to predict the effect of trunk exercise program on muscle activity and gait parameter in chronic stroke patients.

\section{Materials and Methods}

The participants of this study included 6 hemiplegic patients ( 3 males and 3 females) who had a stroke diagnosis and are receiving admission or outpatient treatment in $\mathrm{P}$ rehabilitation center. The general characteristics of the subjects are presented in Table 1. The inclusion criteria for selecting the subjects were as follows: 1) have a history of only one cerebrovascular accident; 2) independent in gait (with or without assistive device); 3) stable cardiovascular status; 4) no significant musculoskeletal problems (fracture, back pain, etc.); 5) MMSE score $>24$ point. The trunk exercise was performed three times a week for a month (Figure 1). One time consists of 3 sets with each set held for $5 \mathrm{~s}$ and maintained for about half an hour. A 1 min rest was allowed between each set. The trunk exercises consisted of six subparts: bridge exercise, curl-up with arm crossed, curl-up with straight reaching (both arm support), curl-up with diagonal reaching (one arm support), abdominal hollowing, and quadruped exercise (Figure 1) [11] [12] [13] [14]. The bridge exercise was performed in a supine position. Both knees were flexed at $90^{\circ}$, and the feet were hip-width apart while resting on the floor. The arms were crossed over the chest to minimize arm support, and the therapist's hands were placed vertically along the lateral aspect of the bilateral knee joint to maintain hip abduction of $30^{\circ}$. The subject was instructed to lift his/her pelvis comfortably at a self-selected speed, while his/her trunk, pelvis, and thigh were aligned in a straight line (hip extension of $0^{\circ}$ ). This position was held for $5 \mathrm{~s}$ (Figure 1) [11]. The curl-up exercise consisted of three parts, namely, shoulder curl-up with arms crossed, curl-up with straight reaching (both arm support), curl-up with diagonal reaching (one arm support), and shoulder curl-up with arms crossed. The knees were flexed at $90^{\circ}$. In the curl-up exercise, the subject elevates his/her trunk until the scapular is lifted from the mat (Figure 1) [12]. In abdominal hollowing, the lower part of the abdominal was drawn up and in toward the spine without moving the trunk or pelvis. A pressure biofeedback unit (Chattanooga Group, Inc., TN37343, USA) was used to ensure that the 


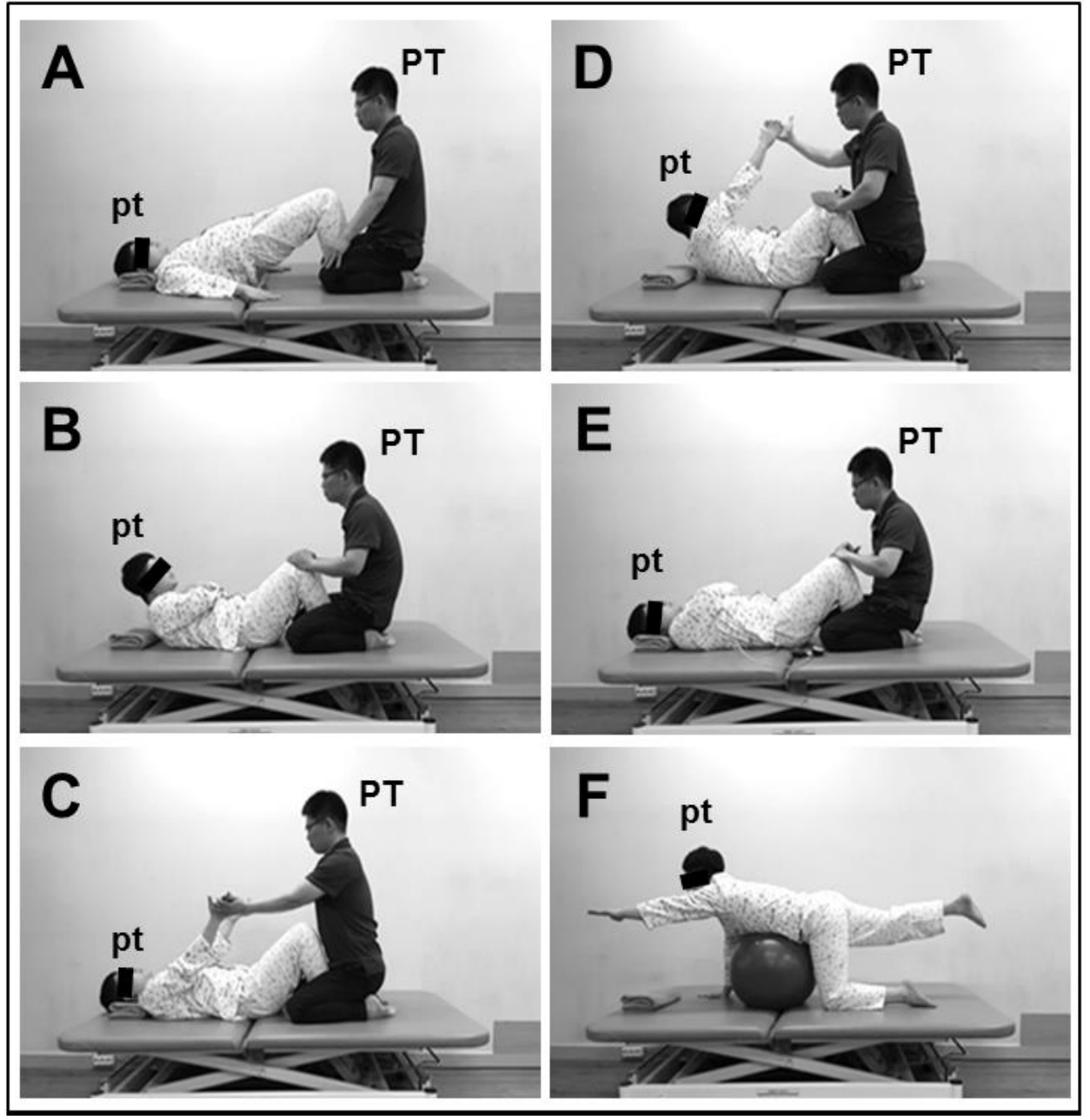

Figure 1. Park et al:: procedure for the trunk exercise program.

subjects performed the exercise correctly. A pressure cuff unit was placed under their lumbar spine and inflated to $40 \mathrm{mmHg}$ before the exercise was performed. When the subject performed the hollowing correctly, the pressure either stayed at $40 \mathrm{mmHg}$ or decreased, and the subjects would tilt his/her abdomen hollow. This position was then held for $5 \mathrm{~s}$ (Figure 1) [13]. The quadruped exercise was initially positioned in a fourpoint stance with knees and hands on the floor (hip flexed to $90^{\circ}$ and hands beneath the shoulder joint). The subject performed a two-point stance with a contralateral arm and leg raise. The subject flexed his/her arms, and the lower body segment was parallel to the trunk. This position was then held for $5 \mathrm{~s}$ (Figure 1) [14]. Outcomes were measured twice, that is, before training and after the four-week training. EMG data were collected using the BTS FREEEMG 1000 (BTS Spa, Italy) device with surface electrodes. The sampling rate was set to $1000 \mathrm{~Hz}$ per channel, and the EMG signals were band-pass filtered from $20 \mathrm{~Hz}$ to $500 \mathrm{~Hz}$. Pre-gelled bipolar silver/silver chloride surface electrodes were placed with an inter-electrode distance of $20 \mathrm{~mm}$. The EMG signals were recorded from the rectus abdominis (RA), external abdominal oblique (EO), transversus abdo- 
minis/internal abdominal oblique (TrA/IO), and elector spinae (ES) of the paretic side of the participants. The electrode attachment regions were as follows: for the RA, $5 \mathrm{~cm}$ above the umbilicus and $3 \mathrm{~cm}$ lateral from the midline; for the EO, approximately 15 $\mathrm{cm}$ lateral to the umbilicus; for the IO, $2 \mathrm{~cm}$ inferomedial to the ASIS; for the ES, $3 \mathrm{~cm}$ lateral to spine and L4 - L5 spinous process. Each electrode attachment region was identified using anatomical landmarks by a qualified physiotherapist and shaved and cleaned using alcoholic wipes. The EMG values of RA and IO muscles were measured from the maximal voluntary isometric contraction (MVIC). The EMG value of the ES measured was the reference voluntary contraction (RVC) because of the difficulty in MVIC movement among stroke patients. The obtained EMG values were the normalized operation (\% MVIC, \% RVC) for comparing the mean. Each muscle performance was measured by MVIC/RVC. The average value was obtained from the exercises performed three times. Contraction time was $5 \mathrm{~s}$, and the normalized values were determined from the middle $3 \mathrm{~s}$ RMS values. During measurements, the examiner verbally encouraged the subjects to stimulate them to perform maximal effort. The gait parameter was measured using the gait analysis system (Gait Trainer 2 Analysis System Inc., Biodex Medical Systems, USA) which was adjusted to the subject's comfortable walking speed [15] [16]. This equipment can analyze the walking parameter, such as walking speed, walking cycle, affected side stance phase, affected side stride length, symmetry index of stance phase, and symmetry index of stride length through a sensor installed on the treadmill floor. Outcomes were measured twice, that is, before training and after the four-week training. The formulas for the symmetry indexes of the stance phase and stride length used in the study were as follows: symmetry index of stride length (\%) = affected side low extremity stride length $(\mathrm{cm}) /$ non-affected side low extremity stride length $(\mathrm{cm}) \times 100 \%$, and symmetry index of the stance phase $(\%)=$ affected side low extremity stance phase (sec)/non-affected side low extremity stance phase $(\mathrm{sec}) \times 100 \%$. The values of the symmetry stance phase and symmetry stride length of closer to 100 mean better gait performance. Data were expressed as the mean \pm standard error (SE) of the measurements. A p-value of $<0.05$ was considered statistically significant. Data were analyzed using SPSS Version 18.0 (International Business Machines, Armonk, USA) for Microsoft Windows. All stroke patients or their next of kin provided informed consent for participation in the study. Furthermore, the protocol for this study was approved by the Committee of Ethics in Research of the University of Yongin, in accordance with the terms of Resolution 5-1-20.

\section{Results}

Table 1 presents the clinical and general characteristics of the stroke patients. No statistical difference was found between pre-training and post-training of MVIC \% in RA and EO, but it tended to increase (Table 2). No statistically difference was found between pre-training and post-training in MVIC \% of TrA/IO and RVC \% of ES (Table 2). However, gait factor was significantly increased in walking speed, walking cycle, and affected stride length (Table 3). Although not significantly, affected side stance phase and symmetry index of stance phase had a significant increase (Table 3 ). 
Table 1. Clinical characteristics of the hemiplegic stroke patients.

\begin{tabular}{cc}
\hline Variable & Hemiplegic stroke patients \\
\hline Age (yrs) & $54.67 \pm 3.45$ \\
Gender & $3(50.00)$ \\
Male (\%) & $3(50.00)$ \\
Female (\%) & $161.33 \pm 4.13$ \\
Height (cm) & $63.00 \pm 3.62$ \\
Weight (kg) & $24.19 \pm 1.02$ \\
BMI (kg/m $\left.{ }^{2}\right)$ & \\
Cause of stroke & $4(66.66)$ \\
Infarction (\%) & $2(33.33)$ \\
Hemorrhage (\%) & \\
Paretic side & $5(83.33)$ \\
Right (\%) & $1(16.66)$ \\
Left (\%) & $13.50 \pm 2.90$ \\
Time post stroke (mo) & $25.67 \pm 0.49$ \\
K-MMSE (score) &
\end{tabular}

All data were presented as the mean \pm SE. BMI: body mass index; K-MMSE: Korean version of the mini-mental state examination.

Table 2. Changes of sEMG in paretic side of trunk muscles after interventions during 4 weeks.

\begin{tabular}{ccc}
\hline \multirow{2}{*}{ Variable } & \multicolumn{2}{c}{ Hemiplegic stroke patients } \\
\cline { 2 - 3 } & Pre-treatment & Post-treatment \\
\hline RA (MVIC \%) & $55.43 \pm 1.23$ & $59.61 \pm 2.20$ \\
EO (MVIC \%) & $51.09 \pm 3.73$ & $52.76 \pm 1.90$ \\
TrA/IO (MVIC \%) & $56.95 \pm 1.52$ & $54.75 \pm 2.21$ \\
ES (RVC \%) & $61.16 \pm 1.76$ & $59.95 \pm 1.44$ \\
\hline
\end{tabular}

All data were presented as the mean \pm SE. sEMG: surface electromyography; MVIC: maximal voluntary isometric contraction; RVC: reference voluntary contraction; RA: rectus abdominis; EO: external abdominal oblique; $\operatorname{TrA} / \mathrm{IO}$ : transversus abdominis/internal abdominal oblique; ES: elector spinae.

Table 3. Changes of gait parameters after interventions during 4 weeks.

\begin{tabular}{ccc}
\hline \multirow{2}{*}{ Variable } & \multicolumn{2}{c}{ Hemiplegic stroke patients } \\
\cline { 2 - 3 } & Pre-treatment & Post-treatment \\
\cline { 2 - 3 } Walking speed $(\mathrm{m} / \mathrm{s})$ & $48.00 \pm 5.63$ & $53.00 \pm 5.38^{*}$ \\
Walking cycle $(\mathrm{cycle} / \mathrm{sec})$ & $0.35 \pm 0.03$ & $0.40 \pm 0.04^{*}$ \\
Affected side stance phase $(\mathrm{sec} / \%)$ & $41.17 \pm 7.63$ & $46.17 \pm 5.77$ \\
Affected side stride length $(\mathrm{cm})$ & $58.00 \pm 5.01$ & $65.83 \pm 5.27^{*}$ \\
Symmetry index of stance phase (\%) & $83.40 \pm 21.20$ & $90.80 \pm 15.50$ \\
Symmetry index of stride length (\%) & $98.46 \pm 20.82$ & $95.99 \pm 9.61$ \\
\hline
\end{tabular}

All data were presented as the mean \pm SE. ${ }^{*}: \mathrm{p}<0.05$. 


\section{Discussion}

The restoration of gait function is an important goal among stroke patients to improve their quality of life [17]. Previous studies reported trunk muscle activity to be related to the gait ability of post-stroke patients [2]. Trunk exercises have a beneficial effect on trunk function, standing balance, and mobility in stroke patients, and they are especially effective to improve balance, gait, and functional ability [3]. This study demonstrated that four weeks of trunk exercises consisting of abdominal hollowing, curl-up, bridge, and quadruped exercise affected muscle activity and spatiotemporal gait parameters. The gait of stroke patients is characterized by short stride length, slow gait velocity, and asymmetric gait pattern [18]. Gait speed is a useful indicator of gait quality among stroke patients. Velocity is easy to measure and is closely related to patients' clinical condition [19]. However, increase in gait velocity without improvements in symmetry suggests that compensatory strategies are retained and amplified [20]. According to our results, truncal exercises can improve the walking speed of stroke patients by increasing the stride length of the paretic side. However, the trunk training did not have a significant effect on improving gait symmetry. Moreover, the short four-week training period did not affect the trunk EMG in the chronic stroke patients. This finding is considered to have been affected by the characteristics of chronic patients, short period of intervention, and small sample size. In summary, the results of the truncal exercise in the EMG values had no significant difference. However, gait speed and stride length of the paretic side were improved despite the short period of intervention. Thus, we expect truncal exercises to help to improve the walking ability of stroke patients. Nevertheless, this study requires further scientific studies [21] [22] [23] [24] [25] to obtain clear effects of trunk exercise program on hemiplegic patients' gait.

\section{References}

[1] Dickstein, R., Shefi, S., Marcovitz, E. and Villa, Y. (2004) Electromyographic Activity of Voluntarily Activated Trunk Flexor and Extensor Muscles in Post-Stroke Hemiparetic Subjects. Clinical Neurophysiology, 115, 790-796.

http://dx.doi.org/10.1016/j.clinph.2003.11.018

[2] Verheyden, G., Vereeck, L., Truijen, S., Troch, M., Herregodts, I., Lafosse, C., Nieuwboer, A. and de Weerdt, W. (2006) Trunk Performance after Stroke and the Relationship with Balance, Gait and Functional Ability. Clinical Rehabilitation, 20, 451-458. http://dx.doi.org/10.1191/0269215505cr955oa

[3] Saeys, W., Vereeck, L., Truijen, S., Lafosse, C., Wuyts, F.P. and Heyning, P.V. (2012) Randomized Controlled Trial of Truncal Exercises Early after Stroke to Improve Balance and Mobility. Neurorehabilitation and Neural Repair, 26, 231-238. http://dx.doi.org/10.1177/1545968311416822

[4] Duarte, E., Marco, E., Muniesa, J.M., Belmonte, R., Aguilar, J.J. and Escalada, F. (2010) Early Detection of Non-Ambulatory Survivors Six Months after Stroke. NeuroRehabilitation, 26, 317-323.

[5] Farley, B.G. and Koshland, G.F. (2000) Trunk Muscle Activity during the Simultaneous Performance of Two Motor Tasks. Experimental Brain Research, 135, 483-496. http://dx.doi.org/10.1007/s002210000551 
[6] Carr, J.H., Shepherd, R.B., Nordholm, L. and Lynne, D. (1985) Investigation of a New Motor Assessment Scale for Stroke Patients. Physical Therapy, 65, 175-180.

[7] Colebatch, J.G. and Gandevia, S.C. (1989) The Distribution of Muscular Weakness in Upper Motor Neuron Lesions Affecting the Arm. Brain, 112, 749-763.

http://dx.doi.org/10.1093/brain/112.3.749

[8] Adams, R.W., Gandevia, S.C. and Skuse, N.F. (1990) The Distribution of Muscle Weakness in Upper Motor Neuron Lesions Affecting the Lower Limb. Brain, 113, 1459-1476. http://dx.doi.org/10.1093/brain/113.5.1459

[9] Davies, P.M. (Ed.) (1990) Problems Associated with the Loss of Selective Trunk Activity in Hemiplegia. In: Right in the Middle, Springer-Verlag, Berlin, 31-65. http://dx.doi.org/10.1007/978-3-642-61502-3_4

[10] Davies, P.M. (Ed.) (2000) Steps to Follow. In: The Comprehensive Treatment of Patients with Hemiplegia, Springer-Verlag, Berlin, 34-49.

http://dx.doi.org/10.1007/978-3-642-57022-3_2

[11] Chung, E., Lee, B.H. and Hwang, S. (2014) Core Stabilization Exercise with Real-Time Feedback for Chronic Hemiparetic Stroke: A Pilot Randomized Controlled Trials. Restorative Neurology and Neuroscience, 32, 313-321.

[12] Beith, I.D., Synnott, R.E. and Newman, S.A. (2001) Abdominal Muscle Activity during the Abdominal Hollowing Manoeuvre in the Four Point Kneeling and Prone Positions. Manual Therapy, 6, 82-87. http://dx.doi.org/10.1054/math.2000.0376

[13] Drysdale, C.L., Earl, J.E. and Hertel, J. (2004) Surface Electromyographic Activity of the Abdominal Muscles during Pelvic-Tilt and Abdominal-Hollowing Exercises. Journal of Athletic Training, 39, 32-36.

[14] Marshall, P.W. and Murphy, B.A. (2005) Core Stability Exercises on and off a Swiss Ball. Archives of Physical Medicine and Rehabilitation, 86, 242-249. http://dx.doi.org/10.1016/j.apmr.2004.05.004

[15] Park, B.S., Kim, M.Y., Lee, L.K., Yang, S.M., Lee, W.D., Noh, J.W., Shin, Y.S., Kim, J.H., Lee, J.U., Kwak, T.Y., Lee, T.H., Kim, J.Y., Park, J. and Kim, J. (2015) Effects of Conventional Overground Gait Training and a Gait Trainer with Partial Body Weight Support on Spatiotemporal Gait Parameters of Patients after Stroke. Journal of Physical Therapy Science, 27, 1603-1607. http://dx.doi.org/10.1589/jpts.27.1603

[16] Park, B.S., Kim, M.Y., Lee, L.K., Yang, S.M., Lee, W.D., Noh, J.W., Shin, Y.S., Kim, J.H., Lee, J.U., Kwak, T.Y., Lee, T.H., Kim, J.Y., Park, J. and Kim, J. (2015) The Effects of a Progressive Resistance Training Program on Walking Ability in Patients after Stroke: A Pilot Study. Journal of Physical Therapy Science, 27, 2837-2840. http://dx.doi.org/10.1589/jpts.27.2837

[17] Nilsson, A., Vreede, K.S., Häglund, V., Kawamoto, H., Sankai, Y. and Borg, J. (2014) Gait Training Early after Stroke with a New Exoskeleton-The Hybrid Assistive Limb: A Study of Safety and Feasibility. Journal of NeuroEngineering and Rehabilitation, 11, 92. http://dx.doi.org/10.1186/1743-0003-11-92

[18] Chu, K.S., Eng, J.J., Dawson, A.S., Harris, J.E., Ozkaplan, A. and Gylfadóttir, S. (2004) Water-Based Exercise for Cardiovascular Fitness in People with Chronic Stroke: A Randomized Controlled Trial. Archives of Physical Medicine and Rehabilitation, 85, 870-874. http://dx.doi.org/10.1016/j.apmr.2003.11.001

[19] Perry, J. (1974) Kinesiology of Lower Extremity Bracing. Clinical Orthopaedics and Related Research, 102, 18-31. http://dx.doi.org/10.1097/00003086-197407000-00004 
[20] Patterson, S.L., Rodgers, M.M., Macko, R.F. and Forrester, L.W. (2008) Effect of Treadmill Exercise Training on Spatial and Temporal Gait Parameters in Subjects with Chronic Stroke: A Preliminary Report. Journal of Rehabilitation Research \& Development, 45, 221228. http://dx.doi.org/10.1682/JRRD.2007.02.0024

[21] Lee, W.D., Lee, J.U. and Kim, J. (2013) Differences in Amplitude of Functional Electrical Stimulation between the Paretic and Nonparetic Sides of Hemiplegic Stroke Patients. Toxicologyand Environmental Health Sciences, 5, 82-85.

http://dx.doi.org/10.1007/s13530-013-0158-5

[22] Kim, M.Y., Kim, J.H., Lee, J.U., Hwang, B.Y. and Kim, J. (2013) The Effect of Low Frequency Repetitive Transcranial Magnetic Stimulation Combined with Range of Motion Exercise on Paretic Hand Function in Female Patients after Stroke. Neuroscience \& Medicine, 4, 77-83. http://dx.doi.org/10.4236/nm.2013.42012

[23] Won, K.J., Lee, K.P., Yu, S., Lee, D., Lee, D.Y., Lee, H.M., Kim, J., Jung, S.H., Naek, S. and Kim, B. (2015) Ketoconazole Induces Apoptosis in Rat Cardiomyocytes through Reactive Oxygen Species-Mediated Park in Overexpression. Archives of Toxicology, 89, 1871-1880. http://dx.doi.org/10.1007/s00204-015-1502-0

[24] Kim, J., Won, K.J., Jung, S.H., Lee, K.P., Shim, S.B., Kim, M.Y., Kim, J.H., Lee, J.U. and Kim, B. (2015) DJ-1 Protects against Undernutrition-Induced Atrophy through Inhibition of the MAPK-Ubiquitin Ligase Pathway in Myoblasts. Life Sciences, 143, 50-57. http://dx.doi.org/10.1016/j.lfs.2015.09.016

[25] Kim, M.Y., Park, B.S. and Kim, J. (2015) Effects of High Frequency Repetitive Transcranial Magnetic Stimulation with Physical Healthy Exercise in Stroke. Toxicologyand Environmental Health Sciences, 7, 160-170. http://dx.doi.org/10.1007/s13530-015-0234-0

\section{Submit or recommend next manuscript to SCIRP and we will provide best service for you:}

Accepting pre-submission inquiries through Email, Facebook, LinkedIn, Twitter, etc. A wide selection of journals (inclusive of 9 subjects, more than 200 journals)

Providing 24-hour high-quality service

User-friendly online submission system

Fair and swift peer-review system

Efficient typesetting and proofreading procedure

Display of the result of downloads and visits, as well as the number of cited articles

Maximum dissemination of your research work

Submit your manuscript at: http://papersubmission.scirp.org/

Or contact nm@scirp.org 